\title{
Imaging synaptic plasticity
}

\author{
Zahid Padamsey and Nigel J Emptage*
}

\begin{abstract}
Over the past decade, the use and development of optical imaging techniques has advanced our understanding of synaptic plasticity by offering the spatial and temporal resolution necessary to examine long-term changes at individual synapses. Here, we review the use of these techniques in recent studies of synaptic plasticity and, in particular, long-term potentiation in the hippocampus.
\end{abstract}

Keywords: synaptic plasticity, long-term potentiation, electrophysiology, optical imaging, $\mathrm{FM}$ dyes, $\mathrm{Ca}^{2+}$ imaging, single particle tracking, pHlourins, FRET, FLIM

\section{Introduction}

Traditionally, electrophysiological recordings and biochemical assays have been used to investigate long-term changes in synaptic efficacy following the electrical, pharmacological, or genetic manipulation of synaptic function. These methodologies limit either the spatial or temporal resolution with which biological processes can be observed and manipulated. For example, the electrophysiological characterization of long-term potentiation (LTP), as reported by increases in the amplitude of evoked postsynaptic potentials, often represents a collective change in transmission efficacy across a population of synapses rather than a direct characterization of plasticity at single sites. Moreover, the use of molecular and pharmacological techniques, although useful in elucidating the role of biochemical pathways in the induction and expression of plasticity, reveal little of the spatiotemporal dynamics of cellular signalling that follow synaptic stimulation. Such dynamics, however, are important in understanding how synaptic processing is altered across space and time following the induction of LTP.

In the past decade, advances in optical imaging, combined with the use and development of fluorescent biosensors, have circumvented the problems associated with traditional experimental techniques by offering unparalleled spatiotemporal resolution of molecular events at synapses. Here, we review the use of optical imaging in recent studies of synaptic plasticity in the

\footnotetext{
* Correspondence: nigel.emptage@pharm.ox.ac.uk
Department of Pharmacology, University of Oxford, Mansfield Road, Oxford

* Correspondence: nigel.emptage@pharm.ox.ac.uk
Department of Pharmacology, University of Oxford, Mansfield Road, Oxford, OX1 3QT, UK
}

(c) 2011 Padamsey and Emptage; licensee BioMed Central Ltd. This is an Open Access article distributed under the terms of the Creative Commons Attribution License (http://creativecommons.org/licenses/by/2.0), which permits unrestricted use, distribution, and reproduction in any medium, provided the original work is properly cited. hippocampus, with a particular focus on how such techniques have been used to assess the 1) presynaptic and 2) postsynaptic expression of LTP, and 3) to examine the spatiotemporal dynamics of plasticity-related signalling.

\section{Presynaptic expression of LTP}

Changes in synaptic efficacy are supported by changes at either pre- or post- synaptic sites [1]. Within the hippocampus, the locus of LTP expression has been a point of contention for many years, in part, due to the difficulties in dissociating the pre- and post- synaptic components of plasticity based on electrophysiological recordings alone [2-8]; many of these difficulties have been overcome by the use of optical imaging.

\section{FM dyes}

The presynaptic component of LTP has been directly investigated by using optical assays of vesicular fusion. One such assay, developed by Betz and Benwick (1992), makes use of fluorescent styryl dyes, such as FM1-43, which readily intercalate with the plasma membrane [9] (Figure 1). During bath application of FM1-43, vesicles generated by endocytosis become dye-labelled. Given that compensatory endocytosis follows activity-dependent vesicle fusion, high-frequency electrical stimulation or elevation of extracellular $\left[\mathrm{K}^{+}\right]$is used to load synaptic vesicles with dye; FM dye within the extracellular fluid or bound to the plasma membrane is then washed off leaving only intracellular vesicles labelled. During a subsequent round of stimulation (generally at a lower frequency than used for loading), dye is released upon vesicular fusion and detected as a decrease in 


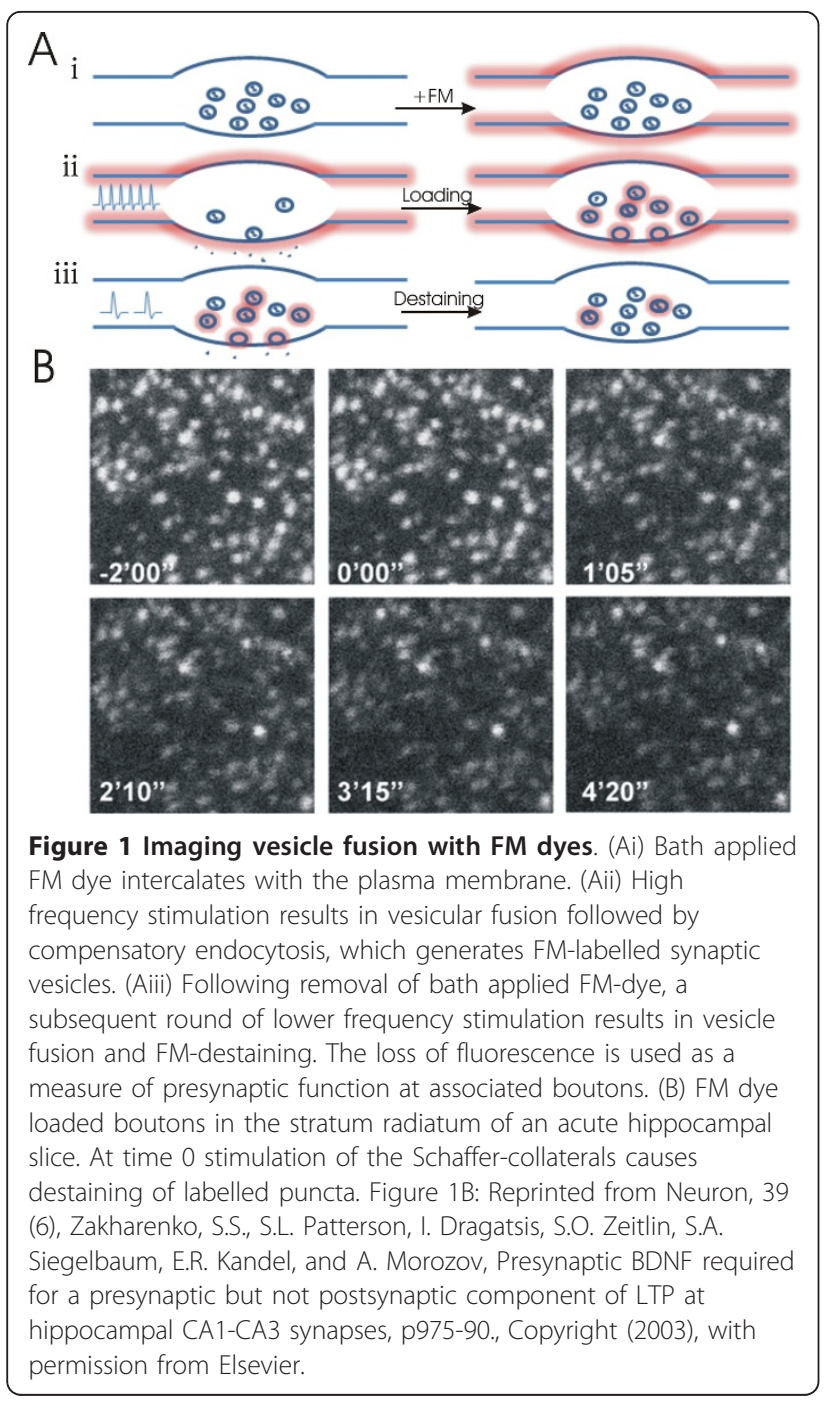

fluorescence at individual synaptic boutons; the magnitude of this decrease is used as a measure of presynaptic efficacy.

High levels of non-specific binding initially restricted the use of FM-dyes to dissociated hippocampal cultures; in recent years, however, such limitations have been ameliorated with the extracellular application of either cyclodextrin (ADAVSEP) to chelate unbound dye, or sulforhodamine, to quench fluorescence, or the use of multi-photon microscopy to minimise background fluorescence [10-19]. In both dissociated cultures and acute slices from the hippocampus, several groups have demonstrated an NMDAR-dependent enhancement of FM-destaining rate following high-frequency stimulation $(\geq 100 \mathrm{~Hz})$, particularly at boutons with low initial rates of destaining $[10,11,15,17,18,20]$; conversely, induction of either NMDAR-dependent or mGluR-dependent LTD has resulted in reduced dyedestaining rates [12-14].
By combining FM-imaging with electrophysiological recordings, Zakharenko et al. $(2001,2003)$ revealed that the induction mechanisms required for the pre- and post-synaptic expression of LTP were partially dissociable $[10,11,21]$. High-frequency stimulation $(200 \mathrm{~Hz})$ of the Schaffer-collaterals readily induced presynaptic changes, - as measured by enhanced FM-destaining rates- the full expression of which was shown to require the activation of L-type voltage-gated calcium channels (L-VGCC) and NMDA-receptors (NMDAR), as well as the release of presynaptic BDNF [10,11,21]. In contrast, low frequency stimulation $(50 \mathrm{~Hz})$ failed to produce detectable changes in FM destaining, though, as with $200 \mathrm{~Hz}$ stimulation, the amplitude of evoked field potentials were augmented; such changes were dependent on NMDA-receptors and presumably reflected an exclusive enhancement of postsynaptic function $[10,11,21]$. The pharmacological and electrophysiological dissociation of the pre- and post-synaptic induction of LTP has also been confirmed using pHlourin-tagged synaptophysin (synaptopHlourin) to monitor vesicle fusion (see [22] for details). Although the presynaptic expression of LTP appears to require high-frequency tetanic stimulation, it should be noted that low-frequency pairing $(0.33 \mathrm{~Hz})$ of single presynaptic spikes with brief, postsynaptic bursting ( 3 action potentials at $100 \mathrm{~Hz}$ ) results in presynaptic potentiation at single synapses [23]; thus high-frequency tetanic stimulation may simply be one way to ensure that postsynaptic bursting is achieved during LTP induction.

One concern with the use of FM-dyes, in addition to their poor signal to noise ratio, is that vesicles and organelles that are not associated with presynaptic terminals can become labelled during dye loading. Without an independent means of confirming the identity of axonal boutons, non-specific labelling has the potential to confound analysis.

\section{$\mathrm{Ca}^{2+}$ sensitive dyes}

In addition to stryl-dyes, $\mathrm{Ca}^{2+}$ indicator dyes have also provided an optical means of assessing transmitter release with single-synapse resolution [23-28]. Singlepulse excitation of afferent fibres, subthreshold for postsynaptic action potential generation, elicit probabilistic $\mathrm{Ca}^{2+}$ transients at stimulated spines (Figure 2A). These transients, although directly generated by $\mathrm{Ca}^{2+}$ influx via NMDARs and voltage-gated channels, are dependent on AMPA-receptor activation and reflect successful release from the presynaptic terminal $[24,27]$. As such, the likelihood of detecting a $\mathrm{Ca}^{2+}$ transient $\left(\mathrm{P}_{\mathrm{Ca}}\right)$ in the spine has been used as a measure of transmitter release probability $\left(\mathrm{P}_{\mathrm{r}}\right)$ at the associated bouton $[23,25,26,28]$.

$\mathrm{Ca}^{2+}$ imaging has been used to investigate the expression of LTP at hippocampal synapses $[23,25,26,28]$. The 


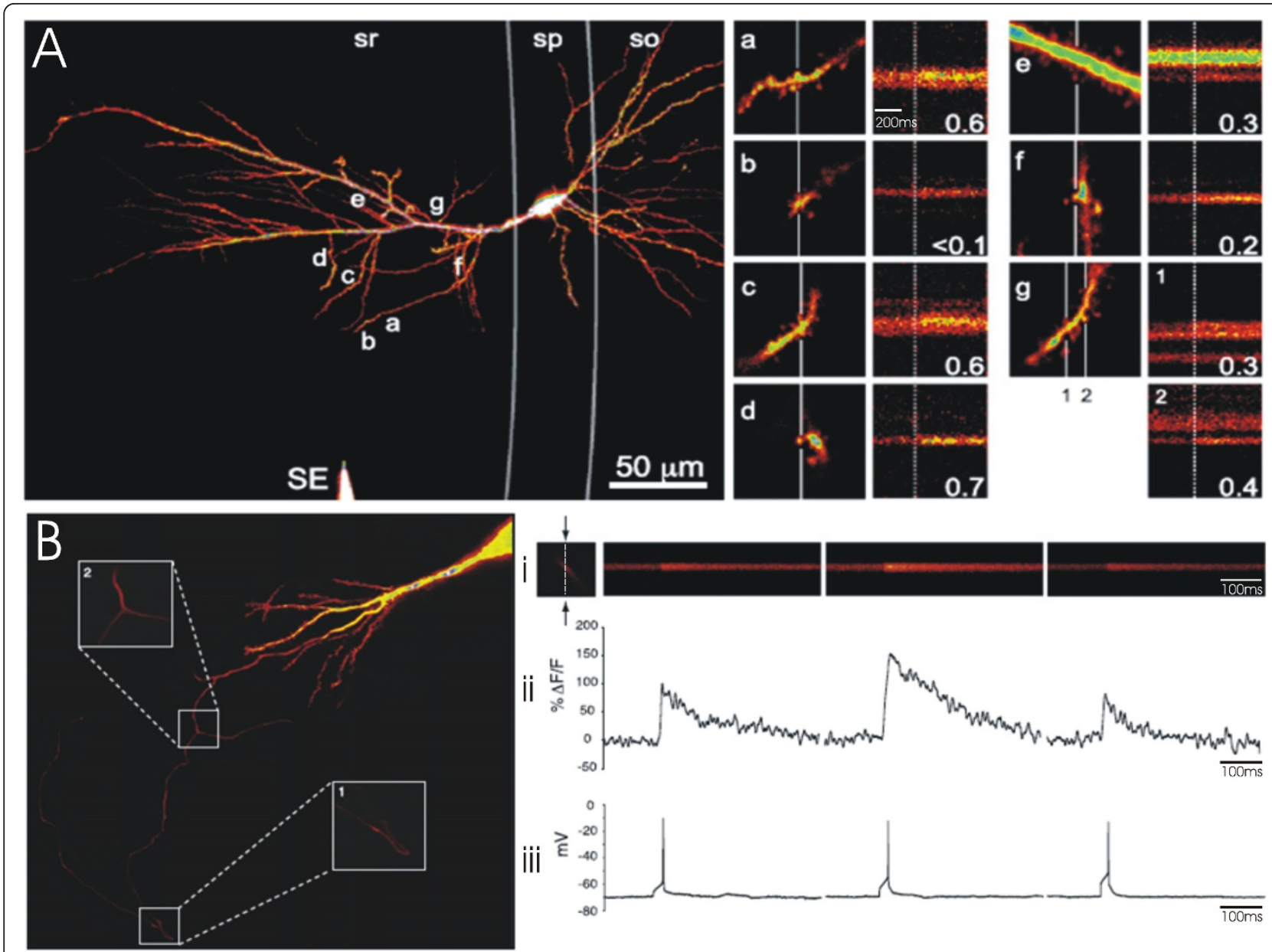

Figure 2 Optical quantal analysis with $\mathrm{Ca}^{2+}$ sensitive dyes. (A) Postsynaptic $\mathrm{Ca}^{2+}$ imaging. (Left) Activation of the axons within stratum radiatum (sr) with a stimulating electrode (SE) resulted in stochastic calcium signalling in several spines (a-g) of a dye-filled CA1 neuron in an acute hippocampal slice. (A; a-g) To enable rapid imaging of calcium events over time, laser scanning was restricted to a line (white vertical line) through responsive spines. The results from a line scan depicting successful transmitter release is presented next to each imaged spine; the broken vertical line indicates the point of stimulation. The probability of detecting a calcium event is displayed under each line scan and is used as a measure of the probability of transmitter release at the associated bouton. (B) Presynaptic $\mathrm{Ca}^{2+}$ imaging. (Left) Axonal projection of CA3 hippocampal neuron loaded with a $\mathrm{Ca}^{2+-}$ sensitive dye. Laser scanning was restricted to a line through an axonal bouton in order to rapidly monitor fluorescence, in response to single action potentials, over time. (i) Three such line scans are presented, along with (ii) the quantified change in fluorescence $(\Delta F / F)$ and (iii) the recorded membrane potential. Note that in the second line scan, the action potential generates a larger calcium transient than in the first and second scan. This high-amplitude calcium transient reflects the additional activation of presynaptic NMDAR following the release of glutamate, and can be used as a measure of the probability of transmitter release at the associated bouton. Figure 2A: Reprinted from Neuron, 62(2), Enoki, R., Y.L. Hu, D. Hamilton, and A. Fine, Expression of long-term plasticity at individual synapses in hippocampus is graded, bidirectional, and mainly presynaptic: optical quantal analysis, p242-53., Copyright (2009), with permission from Elsevier. Figure 2B: Reprinted from Neuron, 68(6), McGuinness, L., C. Taylor, R.D. Taylor, C. Yau, T. Langenhan, M.L. Hart, H. Christian, P.W. Tynan, P. Donnelly, and N.J. Emptage, Presynaptic NMDARs in the Hippocampus Facilitate Transmitter Release at Theta Frequency, p1 109-27., Copyright (2010), with permission from Elsevier.

technique is particularly informative at mossy fibre synapses, where the amplitude of excitatory postsynaptic $\mathrm{Ca}^{2+}$ transients (EPSCaTs) appears to report AMPA receptor activity at individual spines; as such the probability of generating EPSCaTs and the amplitudes of generated EPSCaTs can be used, respectively, to simultaneously monitor the efficacy of both pre- and postsynaptic transmission [26]. Using $\mathrm{Ca}^{2+}$ imaging, Reid et al. (2004) reported that tetanic stimulation $(100 \mathrm{~Hz})$ of the mossy fibres increased $\mathrm{PCa}$ and led to the emergence of new, high-amplitude $\mathrm{Ca}^{2+}$ events at imaged CA3 synapses; since the distribution of EPSCaT amplitudes remained otherwise unchanged compared to baseline, these high-amplitude events likely reflected the recruitment of additional presynaptic release sites at the synapse rather than an increase in the number of 
postsynaptic receptors [26]. Consistent with this notion, the authors reported the emergence of evoked $\mathrm{Ca}^{2+}$ events at previously presynaptically silent synapses, which had initially failed to generate EPSCaTs in response to stimulation, even in the absence of extracellular $\mathrm{Mg}^{2+}$ (under $\mathrm{Mg} 2+$ free conditions, postsynaptic depolarization is no longer required for NMDAR activation, removing the need for AMPARs in the generation of the EPSCaTs). Accordingly, the authors concluded that LTP was expressed at the presynaptic locus of mossy fibre synapses.

Studies using $\mathrm{Ca}^{2+}$ imaging at Schaffer-collateral synapses have similarly reported increases in $\mathrm{P}_{\mathrm{Ca}}$ following tetanic stimulation $[23,25,28]$. However, in contrast to mossy fibre synapses, the amplitude of evoked $\mathrm{Ca}^{2+}$ transients, owing to amplification by $\mathrm{Ca}^{2+}$-induced $\mathrm{Ca}^{2+}$ release from internal stores, does not linearly scale with AMPA receptor activation, and so cannot be easily used to examine postsynaptic changes following LTP [24]. However, Enoki et al. (2009) simultaneously and independently assessed both pre- and post- synaptic components of LTP at Schaffer-collateral synapses by combining $\mathrm{Ca}^{2+}$ imaging with electrophysiological recordings [23]. In one set of experiments the authors stimulated a single axon that made synaptic contact with the recorded neuron, and imaged the responsive spine; single-synapse stimulation was confirmed by obtaining a perfect correlation between the successes and failures of EPSCaTs imaged at the spine, and the successes and failures of EPSPs recorded at the soma. Under such conditions, the authors reported that LTP induction increased the probability of evoking an EPS$\mathrm{CaT}$ (and its associated EPSP) without altering the magnitude of the EPSP. These observations suggest that the presynaptic terminal is the sole locus for the expression of LTP at Schaffer-collateral synapses. It is, however, important to recognise that $\mathrm{Ca}^{2+}$ imaging may incur a selection bias since spines associated with large $\mathrm{Ca}^{2+}$ transients are more likely to be detected when the dendrites are searched for synapses responsive to stimulation. It is therefore possible that imaged spines represent a specific subset of synapses that express LTP presynaptically.

In addition to active synapses, $\mathrm{Ca}^{2+}$-sensitive dyes have been used to investigate the expression of LTP at silent synapses, traditionally viewed as lacking functional AMPA receptors[28]. AMPARs are required to relieve the $\mathrm{Mg}^{2+}$ block of NMDA receptors, and are thus necessary for the generation of EPSCaTs [24]. Spines, at which $\mathrm{Ca}^{2+}$ transients can only be evoked in $\mathrm{Mg}^{2+}$-free solution, are therefore presynaptically active but postsynaptically silent. Following tetanic stimulation, Ward et al. (2006) demonstrated that EPSCaTs could be generated, in $\mathrm{Mg}^{2+}$-containing solution, at previously silent synapses, suggesting the incorporation of functional AMPA recepotrs at these sites [28]. Notably, $\mathrm{P}_{\mathrm{Ca}}$ posttetanus did not differ from baseline values (calculated in $\mathrm{Mg}^{2+}$-free solution), though it increased following a subsequent round of tetanic stimulation. These observations suggest that the locus of LTP expression, whether pre-or post- synaptic, depends on the 'state' of the synapse, whether active or silent.

Although, the detection of $\mathrm{Ca}^{2+}$ events within dendritic spines is generally used to calculate $\mathrm{P}_{\mathrm{r}}$ at Schaffercollateral synapses, McGuinness et al. (2010) recently demonstrated that a similar measure could be derived by examining the amplitude of evoked $\mathrm{Ca}^{2+}$ events within axonal boutons [29] (Figure 2B). The study reported that single action potentials generate either low or high amplitude $\mathrm{Ca}^{2+}$ events within imaged boutons; whereas low amplitude events were shown to be dependent on $\mathrm{Ca}^{2+}$ influx from voltage-gated channels, high amplitude events additionally required the activation of presynaptic NMDA-receptors by glutamate. Given the dependency of high amplitude events on transmitter release, the authors used the probability of evoking such events as a measure of $P_{r}$ at the imaged terminal, and demonstrated that this measure increased following LTP induction. Notably, the use of pre-, as opposed to post-, synaptic $\mathrm{Ca}^{2+}$ events for optical quantal analysis circumvents the observer bias involved in locating EPSCaTassociated spines.

\section{Postsynaptic expression of LTP}

Within the hippocampus, evidence for the postsynaptic expression of LTP has been provided using minimal stimulation and glutamate uncaging paradigms to demonstrate activity-dependent enhancements of responses evoked at single synapses [7,30-35]. Thus, for the past decade there has been a considerable effort to understand the molecular mechanisms underlying the expression of postsynaptic plasticity.

\section{Single particle tracking}

The postsynaptic expression of LTP involves an enhanced sensitivity to glutamate release, for example, by an increase in the number of AMPA receptors at the synapse. New receptors were traditionally thought to originate from an intracellular pool [36], though evidence existed of a second pool of receptors, which were expressed on the plasma membrane but excluded from the postsynaptic density [37]. Recently, the role of these extrasynaptic receptors in synaptic plasticity has been explored using single particle tracking [38,39].

Single particle tracking makes use of fluorescentlytagged antibodies to sparsely label proteins in dissociated cell cultures (Figure 3). For surface receptor labelling, antibodies are conjugated to fluorophores such as 


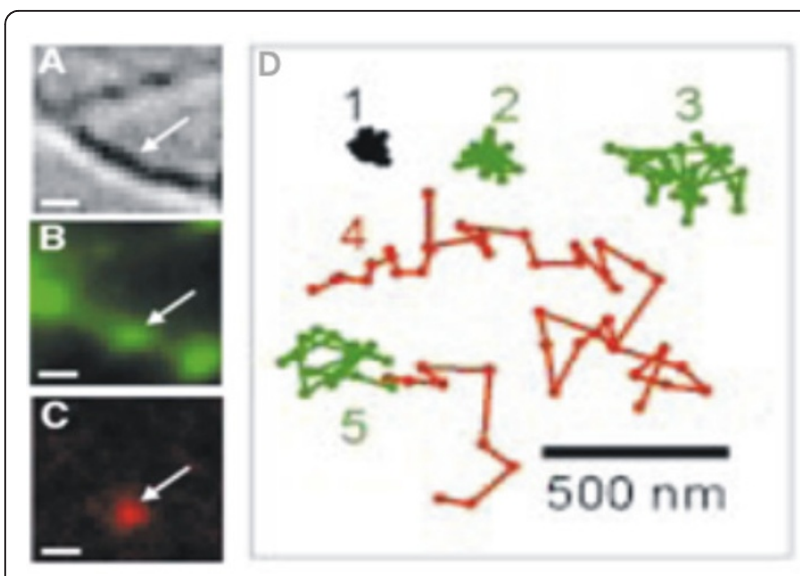

Figure 3 Tracking lateral movements of single receptors. (A) Differential interference contrast imaging of a dendrite in neuronal culture. Simultaneous (B) FM1-43 labelling of presynaptic terminals and (C) single particle labelling of the GluR2 subunit of AMPARs by fluorescently-tagged antibodies allows receptor movements to be observed in synaptic and extrasynaptic space. Scale bar $=1 \mu \mathrm{m}$. (D) Sample receptor trajectories in synaptic (green) and extrasynaptic (red) space; (D1) Trajectory of fluorescently tagged antibodies fixed on a coverslip. Notice that receptor mobility within a synapse is generally more restricted than movement in extrasynaptic space (D2 \& D3 vs.D4). (D5) Trajectory depicting the movement of an extrasynaptic receptor into the synapse. Figure 3: Reprinted by permission from Macmillan Publishers Ltd: [EMBO JOURNAL] (Tardin et al., 22(18):4656-65) copyright (2011).

semiconductor quantum dots, which are quenched within the acidic environment of endocytic vesicles, and are thus only fluorescent when present on the cell surface. Studies also make use of fluorescent markers, such as PSD95 or FM-dye, to delineate synaptic and extrasynaptic space. Tracking of individual AMPA receptors has revealed 1) a mobile pool of synaptic receptors, which constitutively recycle with an extrasynaptic receptor pool, and 2) an immobile pool of synaptic receptors, which are more resistant to exchange [38-41] (Figure 3D).

Notably, receptor trafficking is activity-dependent [40,42-46]. Tardin et al. (2003) reported that the chemical induction of LTP, by bath application of glycine, resulted in a transient increase of synaptic receptor mobility, which was concurrent with a gradual decrease in the number of receptors in the surrounding region, followed by an increase in the proportion of immobile synaptic receptors [41]. Such findings are thought to reflect an activity-driven capture of lateral receptors at the synapse. Consistent with this notion, Heine et al. (2008) demonstrated that high frequency stimulation (50 $\mathrm{Hz}$ ) greatly reduced the mobility of AMPA receptors, particularly at the synapse, and reduced the number of receptor exchanges between synaptic and extrasynaptic space [45]. The immobilization and accumulation of synaptic AMPA receptors was later shown to be NMDAR-dependent, and to require the activation of CAMKII and, its downstream target, stargazin $[42,47]$. In contrast to LTP, Tardin et al. (2003) reported that the induction of LTD was associated with an increase in receptor mobility in and around the synapse, perhaps reflecting the diffusion of previously immobilized receptors out of the synapse [41].

Experiments using single particle tracking have proven valuable for understanding activity-dependent receptor movement in synaptic and extrasynaptic space. However, single particle tracking is restricted to neuronal culture and activity-dependent changes in receptor trajectories are examined following global modifications in synaptic efficacy by chemical insults; LTP or LTD examined under these conditions may not be reflective of synaptic plasticity in vivo.

\section{pHlourins}

Synaptic transmission, following LTP induction, can be enhanced with receptors supplied either from the extrasynaptic pool, via lateral diffusion, or from the intracellular pool, via exocytosis. To investigate the relative contribution of each receptor pool in the expression of LTP several groups have opted for the use of superecliptic pHlourins (SEP) to label AMPA receptors. SEPs are a $\mathrm{pH}$-sensitive variant of green fluorescent protein (GFP) whose fluorescence is quenched in acidic environments. In contrast to GFP, when SEP if fused to the extracellular domain of AMPA receptor subunits, its fluorescence is only reflective of receptors expressed on the membrane surface, and not of those in acidic, endosomal stores (Figure 4A).

Although SEP fluorescence reports surface AMPA receptors, fluorescence recovery after photobleaching (FRAP) a large area of dendrite is reflective of newly exocytosed receptors, since recovery is unlikely to be supported by the lateral diffusion of distant, unbleached receptors. Under such conditions, newly exocytosed receptors are observed as either transient or persistent fluorescent puncta within the imaged area [48] (Figure $4 \mathrm{~B})$. Notably, the number of exocytotic events is enhanced following LTP induction [49,50], in a manner dependent on Ras-ERK, but not CAMKII, signalling [50] (Figure 4B). The majority of fusion events occur within the dendrite [48-50], and, given that the machinery for receptor endocytosis/exocytosis appears to be excluded from the postsynaptic density $[46,51]$, even the small proportion of fusion events that occur within the spine are likely to be excluded from the synapse [50]. Regardless of the location of fusion, fluorescence recovery after photobleaching is greater in spines than in the dendrite following LTP induction $[49,50]$, consistent with the notion that newly exocytosed receptors are mobile and 


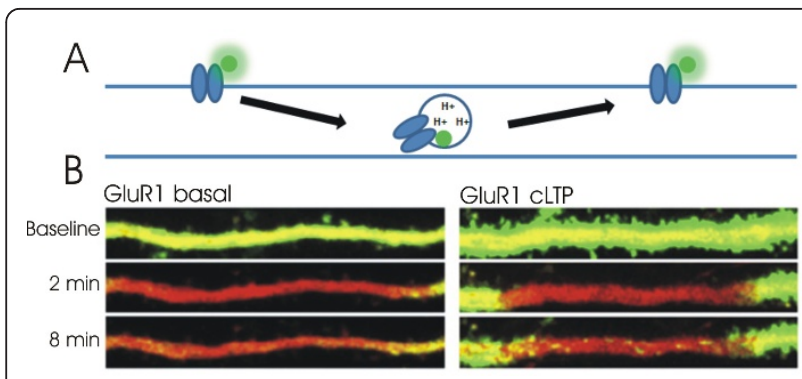

Figure 4 The use of pHlourin tags to image surface receptors and receptor exocytosis. (A) pHlourin fluorescence is quenched within the acidic domain of the endosome, ensuring that only surface receptors are imaged. (B) pHlourins report surface GluR1containing AMPA receptors in a transfected hippocampal neuron in dissociated cell culture. Fluorescence of pHlourin-tagged GluR1 subunits prior to, 2 minutes, and 8 minutes following photobleaching. Fluorescence recovery is mediated primarily by newly exocytosed receptors, as lateral exchange of bleached and unbleached surface receptors is limited under these conditions. Induction of chemical LTP results in a greater number of labelled puncta after photobleaching. Figure 4B: Reprinted from Neuron, 64 (3), Makino, H. and R. Malinow, AMPA receptor incorporation into synapses during LTP: the role of lateral movement and exocytosis, p381-90., Copyright (2009), with permission from Elsevier.

can be preferentially "captured" at synaptic sites [46]. However, the extent to which fluorescence recovery after photobleaching is enhanced at spines following LTP induction is modest when compared to the LTPinduced fluorescence increase without photobleaching, which reflects the contribution of both newly exocytosed and pre-existing surface receptors $[49,50]$. As such, a substantial component of postsynaptic LTP expression appears to be mediated by the synaptic capture of mobile, surface receptors at spines; activity-dependent exocytosis, then, may serve to replenish this mobile pool of surface receptors $[46,49]$.

Fluorescence recovery after photobleaching (FRAP) a small region of interest is rapid and, given the low rates of receptor exocytosis, primarily reflects the lateral diffusion of unbleached receptors; the combined use of SEP and FRAP, therefore, can also be used as to measure the average mobility of surface receptors $[46,49,50,52,53]$. Using this approach, Makino and Malinow (2009) revealed that fluorescence recovery at single spines, 30 minutes after photobleaching, was incomplete in cells expressing the SEP-tagged GluR2, but not GluR1, AMPAR subunit [49]. As such, a portion of GluR2, but not GluR1, containing AMPA receptors appear to be immobilized at the synapse and are resistant to exchange under baseline conditions. Notably, LTP induction, either by glycine application or via glutamate uncaging, resulted in an incomplete recovery of GluR1-SEP fluorescence 30 minutes after photobleaching; fluorescence recovery of GluR2-SEP was unchanged. These findings suggest that
GluR1, but not GluR2, containing AMPARs are preferentially captured at the synapse following LTP induction; it is thought that GluR1-containing AMPARs are then later exchanged for receptors containing the GluR2 subunit in an activity-dependent manner [54].

As a general caveat, the use of pHlourins requires overexpression of a given AMPAR subunit (most often GluR1 or GluR2), which may change the number, distribution, and composition of receptors across synaptic, extrasynaptic, and intracellular pools; it remains to be seen whether these changes fundamentally alter the regulation and expression of LTP.

\section{Synaptic signalling}

Although much research has focused on the expression of LTP, with the development and use of new optical reporters, there has been a growing interest in understanding the spatiotemporal dynamics of synaptic signalling that emerge following the induction of LTP, with a particular interest in the compartmentalized nature of synaptic function.

\section{FRET/FLIM}

In addition to monitoring the distribution of proteins, genetically encoded fluorophores can be engineered to report changes in protein structure or in protein-protein interactions, thus enabling investigators to detect key signalling events in space and time. The detection of such events requires two fluorophores that, when positioned in close spatial proximity $(<100 \AA)$, participate in fluorescence resonance energy transfer (FRET). The extent to which the spectral profile of photon emission resembles that of the acceptor fluorophore, upon excitation of the donor fluorophore, will depend on the proximity of the two fluorophores, which is sensitive to changes in protein confirmation or protein-protein interaction (see Figure 5 for examples of FRET-based reporters).

Measurements of FRET, however, are difficult to interpret and depend on the concentration of the reporter a high intensity ratio of acceptor/donor fluorescence, for example, could be generated by a few reporters generating a strong signal or by many reporters generating a weak signal. Such ambiguities can be circumvented by using fluorescence lifetime imaging microscopy (FLIM), which generates images based on the length of time required for fluorescence signals to decay and is, therefore, independent of reporter concentration [55]. When in close proximity to the acceptor fluorophore, the fluorescence of the donor is quenched and the lifetime of its signal is reduced; this reduction can be used to as a measure of FRET.

FRET/FLIM-based reporters have been designed to detect the activation of CAMKII [56,57], ERK [58], Ras 


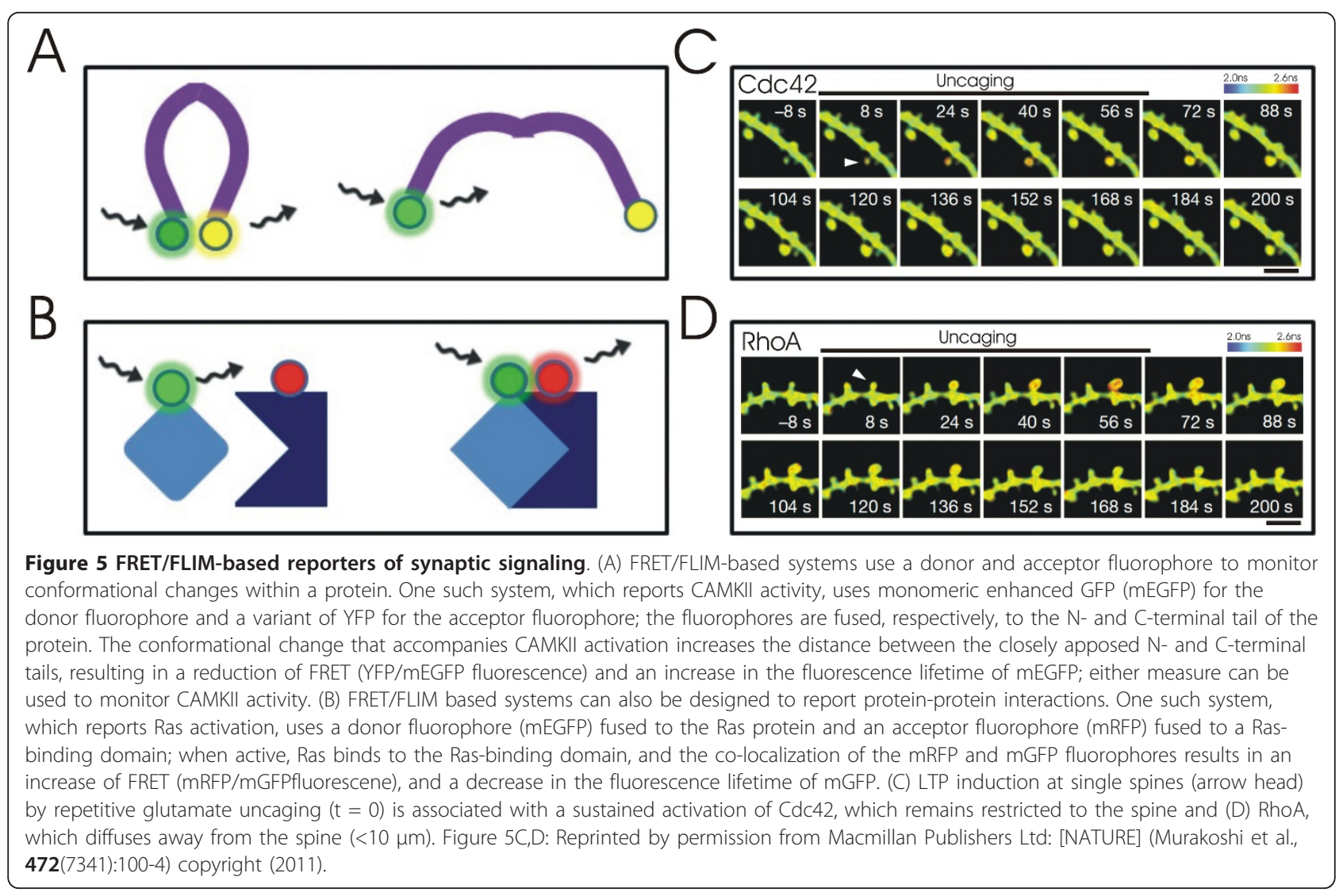

[59], RhoA [60], Cdc42 [60], calpain [61], and to examine the organization of the actin cytoskeleton [62]; these reporters have been designed to be sensitive to changes in protein conformation or protein-protein interactions (see Figure 5A, B for examples). FRET/FLIM-based reporters have been instrumental in understanding compartmentalised synaptic signalling following single spine potentiation with glutamate photolysis. Lee et al. (2009), for example, reported that LTP induction resulted in a transient activation of CAMKII ( 1 min), which was restricted to the stimulated spine; such compartmentalization was thought to result from the rapid kinetics of CAMKII inactivation, which exceeded the kinetics of CAMKII diffusion out of the spine [57]. Single spine potentiation was also associated with the rapid and long lasting (>30 min) activation of the RhoA and Cdc42, which, respectively, was demonstrated to be necessary for the initiation and maintenance of the spine enlargement that accompanied LTP [60]. Interestingly, despite both proteins having similar diffusion kinetics, Cdc42, but not RhoA, activation remained restricted to the spine (Figure 5C, D). The compartmentalization of Cdc42 signalling, in contrast to that of CAMKII, was suggested to arise from a persistent and spatially restricted activation of $\mathrm{Cdc} 42$ within the spine, in combination with rapid deactivation of $\mathrm{Cdc} 42$ in the dendrite [60]. RhoA, on the other hand, diffused up to 5 $\mu \mathrm{m}$ along the length of the dendrite; although such diffusive signalling appeared to have no direct effect on neighbouring spine morphology, it may have altered the threshold for activity-dependent structural changes [60]. In fact, such heterosynaptic changes in synaptic metaplasticity have been reported by Harvey et al. (2008). Their study demonstrated that Ras activation, following LTP induction, rapidly diffused from the stimulated synapse into neighbouring spines within a $10 \mu \mathrm{m}$ radius and remained active for 5-10 min; during this time, the diffuse signalling did not result in a non-specific spread of LTP, but rather, reduced the threshold of stimulation required for LTP induction at neighbouring sites $[34,63]$. Thus, there exists differing degrees of compartmentalized synaptic signalling that regulate the integration of synaptic activity across space and time.

FRET-based designs allow for the creation of a seemingly limitless number of genetically-encoded optical detectors and will likely be useful for studies in vivo. In addition to detecting the activation of various proteins, FRET-based systems have been developed to monitor activity-dependent $\mathrm{Ca}^{2+}$ dynamics, which will also be of tremendous use in future studies of plasticity[64]. 


\section{Photoactivation}

FRET/FLIM-based reporters elucidate the spatiotemporal profile of protein signalling but cannot be used to independently examine the movements of the protein itself. As such, photoactivation is often used in FRET/ FLIM studies to measure the baseline diffusion of a given protein into and out of the spine; such measurements can be important for understanding how protein movement might underlie the spatiotemporal dynamics of its signalling $[57,60,63]$. Photoactivation uses a photactivatable variant of GFP (paGFP), which is fused to the protein of interest. The fluorescence of paGFP with $488 \mathrm{~nm}$ excitation is initially low but stably increases by 100-fold after irradiation with $413 \mathrm{~nm}$ light [65] (Figure $6 \mathrm{~A})$. In this way, photoactivation can be used to monitor the movements of a spatially and temporally defined cohort of proteins (Figure 6B). paGFP has been fused to many of the synaptic proteins for which FRET-based systems have been designed, including CAMKII [56,57], Ras [63], RhoA and Cdc42 [60]. paGFP has also been used to image the distribution and mobility of PSD95 [66] and actin [67] in single spines during and following LTP induction.

In addition to measuring protein movements, photoactivation has been used to directly examine synaptic compartmentalization. Bloodgood \& Sabatini (2005) measured spine/dendrite coupling by activating paGFP in single spines, or their underlying dendrites, and measuring the time constant of equilibration $\left(\mathrm{T}_{\mathrm{e}}\right)$ of the resulting fluorescence signal; $\mathrm{T}_{\mathrm{e}}$ varied greatly across spines, ranging from $\sim 100 \mathrm{~ms}$ to $>5000 \mathrm{~ms}$ [68] (Figure $6 \mathrm{C}, \mathrm{D})$. Synaptic compartmentalization was reported to

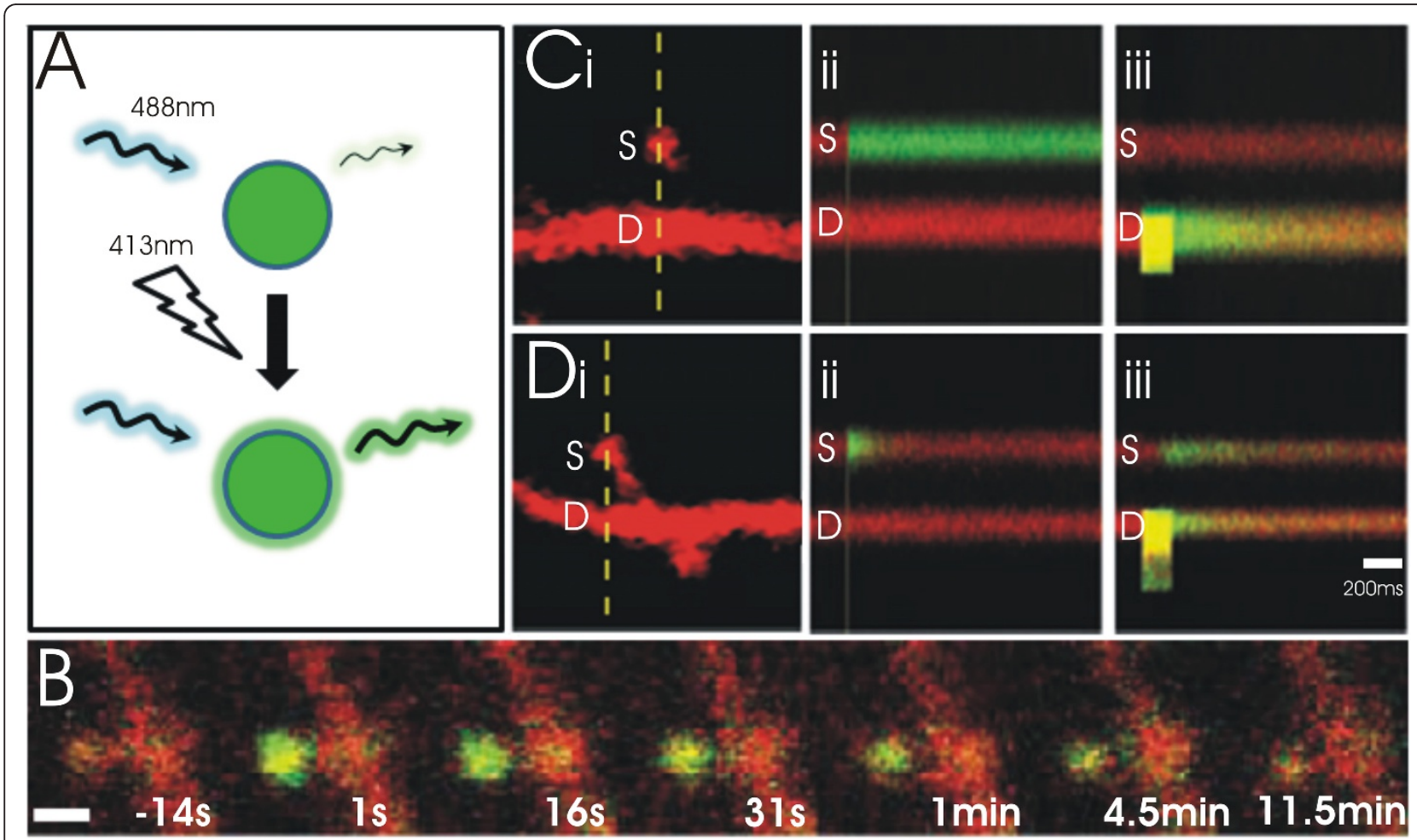

Figure 6 Photoactivatable GFP enables imaging of a cohort of proteins across space and time. (A) The fluorescence of photoactivatable green fluorescent protein (paGFP) with $488 \mathrm{~nm}$ excitation is stably increased 100-fold after illumination with $413 \mathrm{~nm}$ light. (B) Monitoring fluorescence after photoactivation of CAMKII-paGFP in the spine head of a CA1 pyramidal neuron reveals a slow time course of CAMKII diffusion out of the spine. Scale bar $=1 \mu \mathrm{m}$. (C, D) Photoactivation of paGFP in the head and underlying dendrite of two spines of a CA1 pyramidal neuron. Laser scanning was restricted to a single line through the spine head and underlying dendrite (broken line in (i)) to enable rapid monitoring of fluorescence over time. paGFP was photoactivated in the spine (ii) or underlying dendrite (iii) at the time denoted the grey vertical line that is present on each line scan. (Ci) An example of a highly compartmentalized spine. (Cii) Fluorescence in the spine was resistant to decay following photoactivation, reflecting the restricted diffusion of activated paGFP out of the spine. (Ciii) Little fluorescence was also observed in the spine after photoactivation in the underlying dendrite, suggesting that the diffusional coupling of the spine and dendrite is limited. (Di) An example of a poorly compartmentalized spine. (Dii) Fluorescence readily decayed in the spine following photoactivation, reflecting the rapid diffusion of activated paGFP out of the spine. (Diii) Fluorescence was also readily detected in the spine after photoactivation in the underlying dendrite, suggesting strong diffusional coupling of the spine and the dendrite (C iii). Figure 6B: Reprinted by permission from Macmillan Publishers Ltd: [NATURE] (Lee et al., 458(7236):299-304) copyright (2009). Figure 6C,D: From [Bloodgood, B.L. and B.L. Sabatini: Neuronal activity regulates diffusion across the neck of dendritic spines. Science 2005, 310(5749):866-9.]. Reprinted with permission from AAAS. 
be activity-dependent: it was reduced following chronic incubation with TTX and glutamatergic antagonists, and enhanced following the induction of LTP. Spine neck plasticity has also been explored by measuring the rate of fluorescence recovery after the photobleaching of inert dyes (Alexa) in the spine head [69]. Given that synaptic compartmentalization influences the dynamics of calcium and protein signalling both in the spine and dendrite $[57,60,63,67,70,71]$, the activity-dependent modification of the spine neck may serve as a structural correlate for metaplasticity.

\section{Conclusion}

The examination of cellular processes with single synapse resolution has undoubtedly furthered our understanding of LTP. With the continued improvement and development of optical reporters, and, more generally, in optical imaging techniques, our ever increasing ability to study activity-dependent changes in cellular signalling across space and time will offer new insights into the mechanistic basis of synaptic plasticity.

\section{Acknowledgements \\ ZP is supported with funding from the Natural Sciences and Engineering Research Council of Canada (NSERC) and the Clarendon Scholarship (University of Oxford). NJE is supported with funding from the Medical Research Council (UK).}

\section{Authors' contributions}

ZP drafted the manuscript. ZP and NJE revised the manuscript. ZP and NJE read and approved the final manuscript.

\section{Competing interests}

The authors declare that they have no competing interests.

Received: 17 August 2011 Accepted: 29 September 2011 Published: 29 September 2011

\section{References}

1. Bliss TV, Collingridge GL: A synaptic model of memory: long-term potentiation in the hippocampus. Nature 1993, 361(6407):31-9.

2. Kullmann DM, Siegelbaum SA: The site of expression of NMDA receptordependent LTP: new fuel for an old fire. Neuron 1995, 15(5):997-1002.

3. Lisman JE: The pre/post LTP debate. Neuron 2009, 63(3):281-4

4. Manabe T, Nicoll RA: Long-term potentiation: evidence against an increase in transmitter release probability in the CA1 region of the hippocampus. Science 1994, 265(5180):1888-92.

5. Voronin LL, Cherubini E: 'Deaf, mute and whispering' silent synapses: their role in synaptic plasticity. J Physiol 2004, 557(Pt 1):3-12.

6. Lisman J, Lichtman JW, Sanes JR: LTP: perils and progress. Nat Rev Neurosci 2003, 4(11):926-9.

7. Isaac JT, Oliet SH, Hjelmstad GO, Nicoll RA, Malenka RC: Expression mechanisms of long-term potentiation in the hippocampus. J Physiol Paris 1996, 90(5-6):299-303.

8. Nicoll RA: Expression mechanisms underlying long-term potentiation: a postsynaptic view. Philos Trans R Soc Lond B Biol Sci 2003, 358(1432):721-6.

9. Betz WJ, Bewick GS: Optical analysis of synaptic vesicle recycling at the frog neuromuscular junction. Science 1992, 255(5041):200-3.

10. Zakharenko SS, Patterson SL, Dragatsis I, Zeitlin SO, Siegelbaum SA, Kandel ER, Morozov A: Presynaptic BDNF required for a presynaptic but not postsynaptic component of LTP at hippocampal CA1-CA3 synapses. Neuron 2003, 39(6):975-90.
11. Zakharenko SS, Zablow L, Siegelbaum SA: Visualization of changes in presynaptic function during long-term synaptic plasticity. Nat Neurosci 2001, 4(7):711-7.

12. Zakharenko SS, Zablow L, Siegelbaum SA: Altered presynaptic vesicle release and cycling during mGluR-dependent LTD. Neuron 2002, 35(6):1099-110.

13. Stanton PK, Heinemann U, Muller W: FM1-43 imaging reveals CGMPdependent long-term depression of presynaptic transmitter release. J Neurosci 2001, 21(19):RC167.

14. Stanton PK, Winterer J, Bailey CP, Kyrozis A, Raginov I, Laube G, Veh RW, Nguyen CQ, Muller W: Long-term depression of presynaptic release from the readily releasable vesicle pool induced by NMDA receptordependent retrograde nitric oxide. J Neurosci 2003, 23(13):5936-44.

15. Stanton PK, Winterer J, Zhang XL, Muller W: Imaging LTP of presynaptic release of FM1-43 from the rapidly recycling vesicle pool of Schaffer collateral-CA1 synapses in rat hippocampal slices. Eur J Neurosci 2005, 22(10):2451-61.

16. Winterer J, Stanton PK, Muller W: Direct monitoring of vesicular release and uptake in brain slices by multiphoton excitation of the styryl FM 143. Biotechniques 2006, 40(3):343-51.

17. Ahmed MS, Siegelbaum SA: Recruitment of $\mathrm{N}$-Type $\mathrm{Ca}(2+)$ channels during LTP enhances low release efficacy of hippocampal CA1 perforant path synapses. Neuron 2009, 63(3):372-85.

18. Pyle JL, Kavalali ET, Choi S, Tsien RW: Visualization of synaptic activity in hippocampal slices with FM1-43 enabled by fluorescence quenching. Neuron 1999, 24(4):803-8.

19. Kay LM, Laurent G: Odor- and context-dependent modulation of mitral cell activity in behaving rats. Nat Neurosci 1999, 2(11):1003-9.

20. Ryan TA, Ziv NE, Smith SJ: Potentiation of evoked vesicle turnover at individually resolved synaptic boutons. Neuron 1996, 17(1):125-34.

21. Blundon JA, Zakharenko SS: Dissecting the components of long-term potentiation. Neuroscientist 2008, 14(6):598-608.

22. Bayazitov IT, Richardson RJ, Fricke RG, Zakharenko SS: Slow presynaptic and fast postsynaptic components of compound long-term potentiation. J Neurosci 2007, 27(43):11510-21.

23. Enoki R, Hu YL, Hamilton D, Fine A: Expression of long-term plasticity at individual synapses in hippocampus is graded, bidirectional, and mainly presynaptic: optical quantal analysis. Neuron 2009, 62(2):242-53.

24. Emptage N, Bliss TV, Fine A: Single synaptic events evoke NMDA receptor-mediated release of calcium from internal stores in hippocampal dendritic spines. Neuron 1999, 22(1):115-24.

25. Emptage NJ, Reid CA, Fine A, Bliss TV: Optical quantal analysis reveals a presynaptic component of LTP at hippocampal Schaffer-associational synapses. Neuron 2003, 38(5):797-804.

26. Reid CA, Dixon DB, Takahashi M, Bliss TV, Fine A: Optical quantal analysis indicates that long-term potentiation at single hippocampal mossy fiber synapses is expressed through increased release probability, recruitment of new release sites, and activation of silent synapses. J Neurosci 2004, 24(14):3618-26.

27. Reid CA, Fabian-Fine R, Fine A: Postsynaptic calcium transients evoked by activation of individual hippocampal mossy fiber synapses. J Neurosci 2001, 21(7):2206-14

28. Ward B, McGuinness L, Akerman CJ, Fine A, Bliss TV, Emptage NJ: Statedependent mechanisms of LTP expression revealed by optical quantal analysis. Neuron 2006, 52(4):649-61.

29. McGuinness L, Taylor C, Taylor RD, Yau C, Langenhan T, Hart ML, Christian H, Tynan PW, Donnelly P, Emptage NJ: Presynaptic NMDARs in the Hippocampus Facilitate Transmitter Release at Theta Frequency. Neuron 2010, 68(6):1109-27.

30. Isaac JT, Hjelmstad GO, Nicoll RA, Malenka RC: Long-term potentiation at single fiber inputs to hippocampal CA1 pyramidal cells. Proc Natl Acad Sci USA 1996, 93(16):8710-5.

31. Isaac JT, Luthi A, Palmer MJ, Anderson WW, Benke TA, Collingridge GL: An investigation of the expression mechanism of LTP of AMPA receptormediated synaptic transmission at hippocampal CA1 synapses using failures analysis and dendritic recordings. Neuropharmacology 1998, 37(10-11):1399-410.

32. Matsuzaki M, Ellis-Davies GC, Nemoto T, Miyashita Y, lino M, Kasai H: Dendritic spine geometry is critical for AMPA receptor expression in hippocampal CA1 pyramidal neurons. Nat Neurosci 2001, 4(11):1086-92. 
33. Matsuzaki M, Honkura N, Ellis-Davies GC, Kasai H: Structural basis of longterm potentiation in single dendritic spines. Nature 2004, 429(6993):761-6

34. Harvey CD, Svoboda K: Locally dynamic synaptic learning rules in pyramidal neuron dendrites. Nature 2007, 450(7173):1195-200.

35. Kasai H, Tanaka Jl, Horiike Y, Matsuzaki M, Miyazaki T, Ellis-Davies GCR: Protein synthesis and neurotrophin-dependent structural plasticity of single dendritic spines. Science 2008, 319(5870):1683-1687.

36. Man HY, Ju W, Ahmadian G, Wang YT: Intracellular trafficking of AMPA receptors in synaptic plasticity. Cell Mol Life Sci 2000, 57(11):1526-34.

37. Cottrell JR, Dube GR, Egles C, Liu G: Distribution, density, and clustering of functional glutamate receptors before and after synaptogenesis in hippocampal neurons. I Neurophysiol 2000, 84(3):1573-87.

38. Choquet D: Fast AMPAR trafficking for a high-frequency synaptic transmission. Eur J Neurosci 2010, 32(2):250-60.

39. Choquet D: Surface trafficking of receptors between synaptic and extrasynaptic membranes: and yet they do move! Trends Neurosci 2005, 28(3):133-9.

40. Borgdorff AJ, Choquet D: Regulation of AMPA receptor lateral movements. Nature 2002, 417(6889):649-53.

41. Tardin C, Cognet L, Bats C, Lounis B, Choquet D: Direct imaging of lateral movements of AMPA receptors inside synapses. EMBO J 2003, 22(18):4656-65.

42. Bats C, Groc L, Choquet D: The interaction between Stargazin and PSD-95 regulates AMPA receptor surface trafficking. Neuron 2007, 53(5):719-34.

43. Ehlers $M D$, Heine $M$, Groc $L$, Lee $M C$, Choquet D: Diffusional trapping of GluR1 AMPA receptors by input-specific synaptic activity. Neuron 2007, 54(3):447-60.

44. Groc L, Heine M, Cognet L, Brickley K, Stephenson FA, Lounis B, Choquet D: Differential activity-dependent regulation of the lateral mobilities of AMPA and NMDA receptors. Nat Neurosci 2004, 7(7):695-6.

45. Heine M, Groc L, Frischknecht R, Beique JC, Lounis B, Rumbaugh G, Huganir RL, Cognet L, Choquet D: Surface mobility of postsynaptic AMPARs tunes synaptic transmission. Science 2008, 320(5873):201-5.

46. Lu J, Cognet L, Lounis B, Ehlers MD, Choquet D: Endocytic trafficking and recycling maintain a pool of mobile surface AMPA receptors required for synaptic potentiation. Neuron 2009, 63(1):92-105.

47. Opazo P, Labrecque S, Tigaret CM, Frouin A, Wiseman PW, De Koninck P, Choquet D: CaMKII triggers the diffusional trapping of surface AMPARs through phosphorylation of stargazin. Neuron 2010, 67(2):239-52.

48. Yudowski GA, Puthenveedu MA, Leonoudakis D, Panicker S, Thorn KS, Beattie EC, von Zastrow M: Real-time imaging of discrete exocytic events mediating surface delivery of AMPA receptors. J Neurosci 2007, 27(41):11112-21.

49. Makino $H$, Malinow R: AMPA receptor incorporation into synapses during LTP: the role of lateral movement and exocytosis. Neuron 2009, 64(3):381-90.

50. Patterson MA, Szatmari EM, Yasuda R: AMPA receptors are exocytosed in stimulated spines and adjacent dendrites in a Ras-ERK-dependent manner during long-term potentiation. Proc Natl Acad Sci USA 2010, 107(36):15951-6.

51. Park M, Salgado JM, Ostroff $L$, Helton TD, Robinson CG, Harris KM Ehlers MD: Plasticity-induced growth of dendritic spines by exocytic trafficking from recycling endosomes. Neuron 2006, 52(5):817-30.

52. Ashby MC, Maier SR, Nishimune A, Henley JM: Lateral diffusion drives constitutive exchange of AMPA receptors at dendritic spines and is regulated by spine morphology. J Neurosci 2006, 26(26):7046-55.

53. Martin S, Henley JM, Holman D, Zhou M, Wiegert O, van Spronsen M, Joels M, Hoogenraad CC, Krugers HJ: Corticosterone alters AMPAR mobility and facilitates bidirectional synaptic plasticity. PLoS One 2009, 4(3):e4714.

54. Plant K, Pelkey KA, Bortolotto ZA, Morita D, Terashima A, McBain CJ, Collingridge GL, Isaac JT: Transient incorporation of native GluR2-lacking AMPA receptors during hippocampal long-term potentiation. Nat Neurosci 2006, 9(5):602-4.

55. Murakoshi H, Lee SJ, Yasuda R: Highly sensitive and quantitative FRETFLIM imaging in single dendritic spines using improved non-radiative YFP. Brain Cell Biol 2008, 36(1-4):31-42.

56. Takao K, Okamoto K, Nakagawa T, Neve RL, Nagai T, Miyawaki A, Hashikawa T, Kobayashi S, Hayashi Y: Visualization of synaptic Ca2 +/calmodulin-dependent protein kinase II activity in living neurons. $J$ Neurosci 2005, 25(12):3107-12.

57. Lee SJ, Escobedo-Lozoya Y, Szatmari EM, Yasuda R: Activation of CaMKII in single dendritic spines during long-term potentiation. Nature 2009, 458(7236):299-304

58. Harvey CD, Ehrhardt AG, Cellurale C, Zhong H, Yasuda R, Davis RJ, Svoboda K: A genetically encoded fluorescent sensor of ERK activity. Proc Natl Acad Sci USA 2008, 105(49):19264-9.

59. Yasuda R, Harvey CD, Zhong H, Sobczyk A, van Aelst L, Svoboda K: Supersensitive Ras activation in dendrites and spines revealed by twophoton fluorescence lifetime imaging. Nat Neurosci 2006, 9(2):283-91.

60. Murakoshi H, Wang H, Yasuda R: Local, persistent activation of Rho GTPases during plasticity of single dendritic spines. Nature 2011, 472(7341):100-4.

61. Vanderklish PW, Krushel LA, Holst BH, Gally JA, Crossin KL, Edelman GM: Marking synaptic activity in dendritic spines with a calpain substrate exhibiting fluorescence resonance energy transfer. Proc Natl Acad Sci USA 2000, 97(5):2253-8

62. Okamoto K, Nagai T, Miyawaki A, Hayashi Y: Rapid and persistent modulation of actin dynamics regulates postsynaptic reorganization underlying bidirectional plasticity. Nat Neurosci 2004, 7(10):1104-12.

63. Harvey CD, Yasuda R, Zhong H, Svoboda K: The spread of Ras activity triggered by activation of a single dendritic spine. Science 2008, 321(5885):136-40.

64. Tian L, Hires SA, Mao T, Huber D, Chiappe ME, Chalasani SH, Petreanu L, Akerboom J, McKinney SA, Schreiter ER, Bargmann Cl, Jayaraman V, Svoboda K, Looger LL: Imaging neural activity in worms, flies and mice with improved GCaMP calcium indicators. Nat Methods 2009, 6(12):875-81.

65. Patterson GH, Lippincott-Schwartz J: A photoactivatable GFP for selective photolabeling of proteins and cells. Science 2002, 297(5588):1873-7.

66. Steiner P, Higley MJ, Xu W, Czervionke BL, Malenka RC, Sabatini BL: Destabilization of the postsynaptic density by PSD-95 serine 73 phosphorylation inhibits spine growth and synaptic plasticity. Neuron 2008, 60(5):788-802.

67. Honkura N, Matsuzaki M, Noguchi J, Ellis-Davies GC, Kasai H: The subspine organization of actin fibers regulates the structure and plasticity of dendritic spines. Neuron 2008, 57(5):719-29.

68. Bloodgood BL, Sabatini BL: Neuronal activity regulates diffusion across the neck of dendritic spines. Science 2005, 310(5749):866-9.

69. Grunditz A, Holbro N, Tian L, Zuo Y, Oertner TG: Spine neck plasticity controls postsynaptic calcium signals through electrical compartmentalization. J Neurosci 2008, 28(50):13457-66.

70. Noguchi J, Matsuzaki M, Ellis-Davies GC, Kasai H: Spine-neck geometry determines NMDA receptor-dependent $\mathrm{Ca} 2+$ signaling in dendrites. Neuron 2005, 46(4):609-22.

71. Korkotian E, Segal M: Morphological constraints on calcium dependent glutamate receptor trafficking into individual dendritic spine. Cell Calcium 2007, 42(1):41-57.

doi:10.1186/1756-6606-4-36

Cite this article as: Padamsey and Emptage: Imaging synaptic plasticity.

Molecular Brain 2011 4:36.

\section{Submit your next manuscript to BioMed Central and take full advantage of:}

- Convenient online submission

- Thorough peer review

- No space constraints or color figure charges

- Immediate publication on acceptance

- Inclusion in PubMed, CAS, Scopus and Google Scholar

- Research which is freely available for redistribution

Submit your manuscript at www.biomedcentral.com/submit
C Biomed Central 